\title{
Gilberto Freyre e Walter Pater: violência e conservadorismo político atravessados pelo sagrado
}

\section{Gilberto Freyre and Walter Pater: violence and political conservatism crossed by the sacred}

DOI: $10.46814 /$ lajdv3n3-015

Recebimento dos originais: 01/05/2021

Aceitação para publicação: 30/06/2021

\section{Claudio Marcio Coelho}

Doutor em História pela UFES, Brasil. Pesquisador Associado ao NEI - Núcleo de Estudos e Pesquisas Indiciárias/UFES. Membro da AUPPF - Associação Universitária de Pesquisa em Psicopatologia Fundamental

E-mail: claudiomarciocoelho@gmail.com

\section{Marcia Barros Ferreira Rodrigues}

Pós doutora em Ciência Política (UFF) e doutora em História Social (USP), Brasil. Professora Titular da Universidade Federal do Espírito Santo (UFES). Membro da AUPPF - Associação Universitária de Pesquisa em Psicopatologia Fundamental

E-mail: mbfrodrigues@gmail.com

\section{RESUMO}

Neste trabalho, discutimos a repercussão da pequena narrativa literária The Child in the House (1878), do escritor inglês Walter Pater, na formação do cientista social Gilberto Freyre, no período que se inicia com seus estudos universitários nos Estados Unidos, em 1918, até a publicação de sua obra-mestra Casa-Grande \& Senzala, em 1933. A partir da "circularidade das ideias", conforme propõe Carlo Ginzburg, e a concepção de "apetite pelo sagrado", do cientista político Gisálio Cerqueira Filho, da Universidade Federal Fluminense, discutimos como a dimensão do sagrado circulou entre as obras de Walter Pater e Gilberto Freyre, e foi apropriada pelo pensador brasileiro, orientando a construção de sua narrativa histórica, bem como sua predileção por temáticas que estão correlacionadas à estética (desejo de beleza) e religião (desejo de redenção). Discutimos como o sagrado invade, circula e atravessa a produção intelectual de Gilberto Freyre, no período supracitado.

Palavras-chave: Gilberto Freyre, Walter Pater, sagrado, conservadorismo político.

\begin{abstract}
In this paper, we discuss the impact of small literary narrative The Child in the House (1878), the english writer Walter Pater, in shaping the social scientist Gilberto Freyre, in the period beginning with his university studies in the United States in 1918 to publication of his showpiece Casa-Grande \& Senzala in 1933. Based on the "circularity of ideas" as proposed by Carlo Ginzburg, and the concept of "sacred appetite" for the political scientist Gisálio Cerqueira Filho, of the Universidade Federal Fluminense, will discuss how the sacred dimension circulated among the works of Walter Pater and Gilberto Freyre, and was appropriated by the Brazilian thinker, guiding the construction of a historical narrative, and his fondness for themes that are correlated to aesthetics (desire for beauty) and religion (desire redemption). Discuss how the sacred breaks, and circulates through the intellectual production of Gilberto Freyre, the stated period.
\end{abstract}

Keywords: Gilberto Freyre, Walter Pater, sacred, political conservatism. 


\section{INTRODUÇÃO}

No presente artigo abordamos possibilidades metodológicas para o estudo das ideias políticas atravessadas pela cultura religiosa, tendo como base teórica a circularidade das ideias ou apropriação cultural, conforme propõe o historiador italiano Carlo Ginzburg (1989). A partir deste referencial discutimos os efeitos políticos e intelectuais do sentimento religioso do ensaísta e cientista social brasileiro Gilberto Freyre. Bem assim, almejamos interpretar o conservadorismo político de Gilberto Freyre atravessado por sua experiência religiosa na década de 1920. Para tal, tomamos como dimensão empírica e fonte histórica o conto The Child in the House (1878), do escritor inglês Walter Pater, e sua repercussão na produção intelectual de Gilberto Freyre: em sua dissertação de mestrado Social Life in Brazil in the Middle of the 19th Century (1922) e em sua obra seminal Casa-Grande \& Senzala (1933). A conjuntura histórica que analisamos corresponde ao período entre 1918 e 1933: o momento de sua experiência religiosa no Colégio Americano Batista e na Primeira Igreja Batista, ambos do Recife/PE, passando pelos seus estudos universitários nos Estados Unidos, pelo retorno ao Brasil em 1923, culminando com a publicação de Casa-Grande \& Senzala.

Sabemos que o jovem Gilberto Freyre sentia-se seduzido pela Inglaterra desde a infância e a adolescência. Admirava a língua, a história, a cultura, a flama, a excentricidade e o humor inglês. Uma fascinação gestada no ambiente anglófilo do Colégio Americano Batista e pela influência de seu pai Alfredo Freyre (admirador da cultura anglo-saxônica e dos escritores ingleses) e dos missionários batistas, principalmente de seu professor Mr. Muirhead. Gilberto foi batizado na Primeira Igreja Batista do Recife e participou ativamente de suas atividades na Escola Dominical, nos cultos e na pregação do evangelho em bairros operários, entre doentes e moribundos, para os quais lia trechos do Velho e do Novo Testamento. ${ }^{1}$

A relação afetuosa, intelectual e religiosa com o missionário, professor e orientador $\mathrm{Mr}$. Muirhead parece ter repercutido no amadurecimento do jovem Freyre. O ambiente religioso puritano do Colégio Americano Batista e da Primeira Igreja Batista do Recife também atuou decisivamente na formação de seu caráter e perfil psicológico, em seus valores, escolhas, convicções, planos para o futuro intelectual. Aos 16 anos proferiu um discurso no templo da Igreja Batista da rua Imperial, no Recife, intitulado A Bíblia como uma força civilizadora, no qual justificou a superioridade da América do Norte em relação à América do Sul, devido à presença da Bíblia e do puritanismo protestante nos EUA e no Canadá. Também exaltou a "democracia americana" e sua "Constituição livre": conquistas de uma nação que construiu seus alicerces sobre o texto sagrado, a Bíblia (Larreta e Giucci, 2007:43-4).

\footnotetext{
${ }^{1}$ Conforme lemos em documentos do Colégio Americano Batista: Cf. D. L. Hamilton, SEVENTY-TWO e H. H. Muirhead, SEVENTY-THIRD - ANNUAL REPORT OF THE FOREIGN MISSION BOARD-NORTH BRAZIL MISSION, in ANNUAL OF THE SOUTHERN BAPTIST CONVENTION, 1917. Nashville, Tenn: Marshall \& Bruce Company, 1917-1918, pág.154 e 217.
} 
Gilberto "sofreu, como seu irmão e como outros meninos e adolescentes de famílias tradicionalmente católicas, a influência protestante que, nele chegou a ser intensa" (Meneses, 1944:40). Seu interesse pela religião protestante crescia cada vez mais. ${ }^{2}$

Gilberto Freyre viajou para os Estados Unidos em 21 de abril de 1918. Planejara estudar na Universidade de Baylor, na cidade de Waco, Texas. Aluno egresso do Colégio Americano Batista do Recife, onde se destacara por suas realizações, Gilberto foi auxiliado pelos missionários do colégio. O colégio preparou os papéis e documentos com créditos que credenciavam seu aluno promissor para estudar em universidades renomadas nos EUA, mas Gilberto preferiu Baylor: uma universidade provinciana, mas, por outro lado, um centro de excelência de estudo com orientação protestante batista. Desejava ser missionário num futuro próximo, bem assim, estudar em Baylor representava o aprofundamento do projeto religioso iniciado na adolescência. Tão logo chegou no Texas, tornou-se membro da Seventh \& James Baptist Church de Waco e participou ativamente de suas atividades (Larreta e Giucci, 2007; Martins, 2011).

Após quase um ano de seu batismo continuava imbuído de um fervoroso sentimento de missão e compromisso com os valores do puritanismo batista. Admirava as formas plásticas e clássicas da arquitetura antiga de igrejas e monumentos históricos. Logo que chegou aos EUA, visitou Orlando Falcão, seu amigo de colégio e irmão de fé, em Louisville, uma antiga cidade industrial situada à margem do Ohio. Reparou de imediato, que suas casas assemelhavam-se a enormes caixas de papelão, como as de Nova York. Somente os edifícios públicos como os Correios, a Biblioteca Carnegie e as belíssimas Igrejas contrastavam com a monotonia da rude arquitetura industrial da cidade. ${ }^{3}$

De 29 de dezembro de 1919 a 04 de janeiro de 1920, representou o Brasil no VIII Congresso Internacional de Estudantes, realizado em Des Moines, Iowa. Recorrentemente, o jovem Freyre registrava seu apreço pelos traços arquitetônicos das antigas edificações de cidades por onde viajava. E dentre estas, admirou-se das "igrejas francamente belas" de Des Moines. "Que seria das cidades americanas se lhe arrancassem suas igrejas?”, pergunta Gilberto Freyre. No congresso, onde reuniramse estudantes dos Estados Unidos, Canadá e de outras trinta e oito nações, os desafios e problemas sociais, políticos, econômicos, estudantis foram debatidos "à luz do Cristianismo" e de "sua essência". O congresso foi promovido pela Federação Mundial de Estudantes Cristãos, uma entidade criada em 1895, pelo metodista e entusiasta por missões John Mott. A federação nasceu no seio do Student Volunteer Moviment of North America, um movimento gestado em 1886, durante as "conferências de

\footnotetext{
${ }^{2}$ Conforme lemos em documentos da Primeira Igreja Batista do Recife: Cf. LIVRO DE ACTAS DA PRIMEIRA EGREJA BAPTISTA DO RECIFE, 1915 a 1920, p.422; ACTAS DA PRIMEIRA EGREJA, pág.447 e 450.

${ }^{3}$ Conforme lemos na fonte. Tempo morto e outros tempos: trechos de um diário de adolescência e primeira mocidade, 1915-1930. Gilberto Freyre. Rio de Janeiro: José Olympio. 1975.
} 
verão do famoso evangelista e reavivalista americano Dwight L. Moody", realizadas em Mount Hermon, Massachusetts (Siepierski, 2008:94). Do missionário John Mott registrou: "Tive a honra de apertar a mão a este grande homem e de dizer-lhe quanto o admiro". 4

Em Baylor University, de 1918 a 1920, o jovem Freyre realizou estudos em Artes Liberais e especializou-se em Ciências Políticas e Sociais. Como aluno de Joseph Armstrong - um professor apaixonante, dinâmico e entusiasmado com o conhecimento e com a literatura inglesa - sentiu-se ainda mais cativado pelas possibilidades de estudos sobre o ensaísmo. Dentre as vinte e duas disciplinas que cursou em Baylor, nove pertenciam ao Departamento de Língua e Literatura Inglesa, dirigido pelo Dr. Armstrong, que ministrava cursos sobre Dante, Renascimento italiano, Shakespeare, Goethe, literatura vitoriana, poesia e drama contemporâneo, obras primas da literatura, composição e retórica. Neste último curso, obrigatório para alunos iniciantes, o jovem Freyre manteve contato com ensaístas britânicos que marcariam para sempre sua trajetória intelectual e repercutiriam afetivamente em suas escolhas, hesitações, projetos e livros publicados. Assim, retomou leituras de Bacon e Milton; iniciou leituras apaixonantes em Dryden, Browne, De Quincey, Steele, Addison, Johnson, Hazlitt, Defoe, Savage, Landor, Huxley, Trackeray, Newman, Bennett, Hearn, G. K. Chesterton e Walter Pater. Também desenvolveu estudo sistemático de autores outrora conhecidos, de leituras mais aventurosas que dirigidas como Swift, Lamb, Carlyle, Ruskin, Macaulay. Sentia-se seduzido pela literatura de ficção, uma literatura psicológica, bem como pela poesia psicológica e filosófica de Chaucer a Browning, passando por Shakespeare (Pallares-Burke, 2005; Larreta e Giucci, 2007).

O professor Joseph Armstrong ensinou-lhe particularidades e possibilidades de aplicação do ensaio: um gênero que se define simultaneamente como pessoal, claro, explícito, despretensioso, agradável, um tanto meditativo e coloquial (Coelho, 2007). Dentre os diversos autores estudados pelo jovem Freyre nos cursos ministrados pelo professor Armstrong, dois ensaístas ingleses repercutiram decisivamente em suas escolhas teóricas, preferências temáticas e amadurecimento afetivo-intelectual. São eles: Walter Pater e G. K. Chesterton. Escritores que robusteceram a atração freyriana por sentimentos religiosos pujantes; sentimentos outrora despertados em sua infância, mas, principalmente, durante sua adolescência protestante-batista no Recife/PE. Tais sentimentos repercutiriam decisivamente no estudante latinoamericano e no intelectual que se tornaria (Coelho 2016).

\footnotetext{
${ }^{4}$ Conforme lemos na fonte: Tempo de aprendiz: artigos publicados em jornais na adolescência e na primeira mocidade do autor, 1918-1926. Gilberto Freyre. São Paulo: IBRASA; Brasília: INL. 1979. Citação na página 72.
} 


\section{A NARRATIVA LITERÁRIA DE WALTER PATER EM THE CHILD IN THE HOUSE} (1878)

Walter Horatio Pater (1839-1894) foi um ensaísta inglês requintado e erudito, escritor de ficção, crítico literário e de arte. O conto The Child in the House só foi publicado como livro em 1894, o ano da morte do autor, pela editora privada do Rev. Henry Daniel de Oxford. Para nosso trabalho utilizaremos a edição da Série Vest Pocket, publicada em 1909, nos Estados Unidos. Esta edição é uma reprodução da $14^{\mathrm{a}}$ edição americana, impressa em 1908, pela Série Brocade.

Toda a narrativa do conto realiza-se em torno do personagem Florian Deleal. Inicia-se com um encontro casual, seguido de uma ação de boa vontade e de uma recompensa singela, recebida por Florian em virtude de sua piedade. Caminhava Florian em uma tarde quente, quando ultrapassou um velhinho à beira da estrada. Sentiu-se consternado com o cansaço do velhinho e decidiu ajudá-lo com a carga que carregava. Ao ouvir do homem sua história, algo de muito especial chamou-lhe a atenção, quando este citou o pequeno lugar onde Florian viveu sua infância e para o qual nunca mais retornou. $\mathrm{Na}$ noite daquele mesmo dia foi recompensado por sua boa ação, pois sonhou com o lugar, especialmente com a casa, onde viveu quando criança. O sonho realizou em Florian um "trabalho de mais fina memória”, pois em sua experiência onírica vislumbrou:

O verdadeiro aspecto do lugar, especialmente da casa onde ele viveu quando criança, o estilo das suas portas, suas lareiras, suas janelas, seu próprio perfume o acompanhou em seu sono durante uma temporada; apenas, com matizes mais musicalmente misturadas na parede e no chão, e alguma luz mais fina e sombra entrando e saindo ao longo de suas curvas e ângulos, e com todas as suas pequenas esculturas graciosas (PATER, 1909:3-4).

Acordou... Suspirou com lembranças de quase trinta anos. Vibrou de prazer. Sorriu. Decidiu iniciar um projeto outrora imaginado: observar alguns pormenores na história de seu espírito, em sua jornada mental. Começou a pensar de si mesmo a partir da velha casa. Ocorreu-lhe uma sucessão de suaves lembranças: "Naquela casa meio-espiritualizada ele podia ver o melhor, mais uma vez, a gradual expansão da alma, que tinha vindo a ser, lá - e que de fato, por meio da lei que torna os objetos materiais em torno deles um elemento tão grande nas vidas das crianças..." (Pater, 1909:5).

Florian recordou traços da velha casa e espaços que compõe seus lugares de memória. Espaços atravessados por afetos e sinestesia. Quase nada escapou de sua memória afetiva: "tudo isso atuava na sua fantasia infantil" (Pater, 1909:10). Mas que fantasia? O sonho um pouco acima de si mesmo e o esquecimento da contradição. Assim, a mais doce e tenra de todas as fantasias de Florian transfigurouse em desejo intenso pelo passado sem máculas.

A sensibilidade sinestésica de Florian proporcionou-lhe recordações poéticas sobre o perfume da casa, do jardim, das flores, das frutas, o zumbido das abelhas, o frescor, o frio, o calor, a escuridão: 
Assim, a criança (..) continuou a viver lá calmamente; (..) enquanto ele se sentavac perto da janela onde havia uma gaiola pendurada logo abaixo dela, e sua mãe lhe ensinou a ler, e pensava na facilidade com que aprendeu e na velocidade da sua memória. O perfume das pequenas flores do pé de lima cobriram o ar como a chuva; enquanto o tempo parecia se mover lentamente ao som do zumbido das abelhas, até que quase parou nas tardes de junho.

(...).

Também, como sentiu essa pressão do mundo sensível sobre ele, em seguida, como ocorria muitas vezes depois, aliviria um outro tipo de questionamento curioso como as ultimas impressões de olhos e ouvidos poderiam ocorrer com ele, como elas o encontrariam - o perfume da ultima flor, o amarelo suave da última manhã, o último reconhecimento de alguns objetos de afeição, mão ou voz; não poderia ser senão aquele último olhar dos olhos, antes do fechamento final, seria estranhamento vívido; alguém ficaria com as lágrimas quentes, o grito, o toque do espectador melancólico, profundamente impressionado! Ou seria talvez uma mera frágil retirada de todas as coisas, grandes ou pequenas, para longe de alguém, para uma distância igual? Pois com esse desejo de beleza física misturou-se o medo prematuro da morte - o medo da morte intensificado pelo desejo de beleza (PATER, 1909:11, 31-2).

Sua memória sinestésica capturou pormenores que aguçaram sentidos poéticos e despertaram a saudade da tradição. Os doces sentidos transportaram seus sentimentos para a contemplação e para o religare que desejava. Assim, ocorreu-lhe uma relação simbiótica entre casa, religião, paixão e medo da morte. Nas linhas poeticamente concebidas, vislumbramos um menino sensível às impressões belas. Florian estava tomado pelo desejo de beleza.

Florian amava a pureza e as formas religiosas. Outrossim, também amava as imagens nos livros religiosos, a representação do anjo lutador que agarrou Jacó, os sinos e as romãs presas nas vestes de Aaron. Este amor da criança pelas formas externas de religião e o apetite do coração pela pureza (tomismo) são sintomas de seu desejo de redenção, para suavisar os sofrimentos e dignificar a vida.

$\mathrm{Na}$ adolescência Pater desligou-se da Igreja Anglicana e desistiu de seus intentos de tornar-se ministro religioso. Sua absorção das ideias evolucionistas de Darwin e do racionalismo de outros pensadores geralmente é interpretada como uma perda de fé.

Este distanciamento, para muito além da mera expressão de qualquer significado de perda de fé, ou mesmo da elevação do racionalismo como novo paradigma iluminista, seria indicativo da constituição de um "novo lugar" para o domínio das idéias religiosas. Tal lugar seria constituído, assim como para o personagem Florian, não mais diretamente pela razão ou pela fé, mas pelo prazer sensitivo e extasiado das luzes da igreja, dos dias contemplativos, "all that belonged to the comely order of the sanctuary" (CERQUEIRA FILHO e NEDER CERQUEIRA, 2008:2).

Entretanto, a religião retornou nas franjas da narrativa literária de Pater. Em sua narrativa ficcional tudo (ou quase tudo) está impregnado de sentimento religioso, de sacralidade, de religiosidade extasiante. A velha casa de sua infância, na qual recordou-se dos momentos de ternura, fantasias, descobertas, medos e alegrias, está impregnada de um encanto secreto e melancólico, como manifestação de uma saudade interminável. Há no conto um sentimento forte de casa, que atravessa o 
personagem Florian. A casa fantasiada por Pater é lugar sagrado, espaço de sacralização da vida, do mundo, das relações sociais, um santuário onde se pode descansar das amarguras e sofrimentos que a vida nos impõe. Nela, o divino e o sagrado deslizam para a relação sensível com a vida material, com as coisas. Porém, a casa naturalizada pela memória infantil de Florian também tornou-se lugar de sujeição.

Podemos inferir que a sensibilidade sinestésica de Florian Deleal manifestou-se como sensibilidade romântica. Neste sentido, o prazer sensitivo pelos cheiros, sons, cores e texturas assumiu a aura de contemplação, reverência e sacralidade: a "contemplação estupefante". Ocorreu-lhe a sacralização dos sentidos, os sentidos tornaram-se inebriados. Esta sinestesia provocou extasia pelo belo sacralizado: o desejo de beleza amalgamado com o desejo de redenção do sofrimento, da contradição. Desta feita, podemos perceber que os efeitos políticos do amor de Florian pelas formas religiosas foram: a fantasia extasiante de um passado sem máculas, o esquecimento do pathos violento nas relações históricas e a defesa do conservadorismo romântico das ideias e das relações políticas. $\mathrm{O}$ “encantamento do êxtase" transformou-se em "passividade anestésica" (Ibidem, 2008:6).

\section{A REPERCUSSÃO DA LITERATURA DE PATER NA PRODUÇÃO INTELECTUAL DE FREYRE (1922 A 1933)}

Gilberto Freyre chegou à Nova York em janeiro de 1921. A maior metrópole americana, cidade cosmopolita e marcantemente rica por seu ambiente intelectual, científico, cultural contrastava muitíssimo com a provinciana Waco, no Texas. A diversidade de ambientes, estudos, conferências, pesquisas, contatos com alunos e professores estrangeiros, paisagens díspares, atrações em arte e cultura, museus e bibliotecas favoreciam o aprendizado e a interlocução com grandes nomes da literatura e das ciências humanas e sociais: intelectuais como o antropólogo Franz Boas, o filósofo John Dewey, os historiadores William Shepherd, Alfred Zimmern, Carlton Hayes, Clarence Haring, Fox e Kendrick, o sociólogo Franklin Giddings, o economista Seligman, o professor de direito John B. Moore. $^{5}$

Era um frequentador assíduo de bibliotecas, acervos documentais, monumentos históricos, museus, teatros, igrejas. Interessante constatar que em quase todos os registros de suas viagens por cidades americanas - também na Europa e no Brasil - sempre dedicou uma parcela importante de seu tempo em passeios extasiantes por Capelas e Igrejas locais. Apreciava as formas e as representações

\footnotetext{
${ }^{5}$ Conforme lemos na fonte. Tempo morto e outros tempos: trechos de um diário de adolescência e primeira mocidade, 1915-1930. Gilberto Freyre. Rio de Janeiro: José Olympio. 1975.
} 
do sagrado nas Igrejas mais antigas. ${ }^{6}$ Estava tomado pelo amor às formas externas da religião. Para ele, era como se Deus estivesse na beleza, assim como aprendera com a estética de Pater.

Realizou vasta pesquisa sobre a formação do Brasil e da América Latina em bibliotecas de Nova York e na cidade de Washington. Assim, concluiu seus estudos de pós-graduação em 1922 e apresentou sua dissertação de mestrado Social life in Brazil in the middle of the 19th Century: um ensaio históricosociológico declaradamente comprometido com a visão positiva do passado brasileiro. Registrou no prefácio da dissertação a importância de seu contato com o ensaísmo de Walter Pater e citou a forma como o escritor inglês estudava a história: "para saber como vivia o povo, que trajes usava, que aparência tinha". Neste mesmo sentido, Freyre desejava "saber" como fora a vida do brasileiro nos meados do século XIX (Freyre, 1964:69).

No trecho que selecionamos e que citamos a seguir, podemos surpreender o menino Gilberto inspirando e orientando a narrativa histórica, assim como a criança de Pater, Florian Deleal, orientou sua narrativa literária:

A preparação dêste ensaio começou, de certo modo, inconscientemente, quando, ainda menino, costumava (...) fazer perguntas à avó materna - Dona Francisca Barradas da Cunha Teixeira de Mello - sôbre os "bons tempos antigos". Na família ela era a única pessoa que admitia, então, que os tempos antigos tinham sido bons. Todos os outros pareciam se "futuristas" ou "pós-impressionistas" de uma ou outra espécie.

Ouviu (...) quando menino, relatos sôbre o passado íntimo da sua gente, de outras pessoas, então de idade tão avançada que algumas, embora de todo lúcidas, já falavam com voz tremida e, quando andavam, já arrastavam tristonhamente os pés, como Dona Maria Rabelo de Oliveira. Também a Viúva Augusto de Carvalho. O próprio Augusto Ferreira de Carvalho (...). De velhos menos ilustres ouviu (...) na meninice muitas estórias e alguma história - estórias de fadas, de princesas e de bichos e história da gente brasileira. Impossível deixar de referir-se à preta velha Felicidade (Dadade), antiga escrava da família Cunha Teixeira... (FREYRE, 1964: 69-70).

A obra-mestra de Gilberto Freyre, Casa-Grande \& Senzala, publicada em 1933, constitui, juntamente com Evolução Política do Brasil (1934), de Caio Prado Jr e Raízes do Brasil (1936), de Sérgio Buarque de Holanda, um grande esforço ensaístico e interpretativo sobre a formação do Brasil. Nela, Freyre considerou a casa como um santuário de sentimentos religiosos que atravessam a vida de seus moradores em todas as instâncias, assim como Pater pensou a casa em seu conto:

A história social da casa-grande é a história íntima de quase todo brasileiro: de sua vida doméstica, conjugal, sob o patriarcalismo escravocrata e polígamo; da sua vida de menino; do seu cristianismo reduzido à religião de família e influenciado pelas crendices da senzala. (...) Estudando a vida doméstica dos antepassados sentimo-nos aos poucos nos completar: é outro meio de procurar-se o "tempo perdido". Outro meio de nos sentirmos nos outros - nos que viveram antes de nós; e em cuja vida se antecipou a nossa. É um passado que se estuda tocando

${ }^{6}$ Ibidem. 
em nervos; um passado que emenda com a vida de cada um; uma aventura de sensibilidade, não apenas um esforço de pesquisa pelos arquivos (FREYRE, 1995: lxv).

Em A Decadência do Ocidente (1918-1922), Oswald Spengler demonstrou que a casa é uma força cósmica e misteriosa que atua na coesão dos que convivem estritamente juntos. Spengler considerou as "culturas como sujeitos, e não como objetos, do acontecer histórico" (Freyre, 1968: 183). Semelhantemente, Freyre considerou a casa-grande colonial brasileira um centro de coesão patriarcal, religiosa, econômica, política, cultural e afetiva. Sua apreciação dos traços característicos da arquitetura das casas-grandes coloniais revelou-lhe detalhes da vida social no início da colonização portuguesa nos trópicos. A arquitetura da casa-grande de engenho expressava a estrutura das relações sociais, marcadas por violências e antagonismos entre brancos e negros; mas Freyre, em sua fantasia, acentuou a prevalência das relações afetivas confraternizantes entre Senhores e Escravos.

$\mathrm{Na}$ casa encontramos indícios da vida afetiva marcada por uma brutal violência e da vida material do Brasil colonial. Estes, por sua vez, denunciam a memória da vida religiosa, dos cheiros, sabores, cores, sexualidades, corpos, sentimentos, crenças, rituais da vida cotidiana. Ao sacralizar a casa, a comida e suas vivências, Freyre revela de forma velada um autoritarismo afetivo (Cerqueira Filho, 2005) que produz efeito duplo em relação ao sagrado, a saber, contentamento e apaziguamento.

A memória sinestésica e o sentimento religioso presentes na obra-mestra de Gilberto Freyre revelam a apropriação freyriana do conto de Walter Pater pela via do prazer sensitivo, cujo efeito ideológico provoca a contemplação religiosa do belo, dos sabores, gostos, cheiros e sentidos em conciliação, esvaziando a contradição e o conflito, inerentes à escravidão. Sua narrativa é atravessada pela extasia (sentimentos extasiantes, eufóricos) e anestesia (sentimentos de reverência, sujeição). E nessa sujeição, o pensamento fica inebriado, sem reação, submisso a fantasia de conciliação/confraternização entre os pares antagônicos estruturantes da sociedade brasileira: senhores e escravos. De mais a mais, a memória sinestésica - resgatada por Gilberto Freyre - apazigua a contradição do processo de colonização do Brasil, expresso na luta e nos conflitos religiosos entre a Casa Grande e a Igreja Católica, especificamente representada pelo embate político entre o jesuitismo e o pater poder dos Senhores de Engenho.

Freyre foi um típico representante da anglofilia que influenciou toda sua geração. Como demonstramos alguns autores britânicos foram decisivos na sua formação inicial entre 1917-1923. Foi a partir das redes estabelecidas entre intelectuais britânicos de vertentes variadas da literatura, filosofia, história e sociologia que emergiu (repercutiu) no pensamento de Freyre a ideia central que orientou sua interpretação da relação casa-grande-senzala: a noção de "equilíbrio de antagonismos". Essa foi a base teórica do paradigma por ele criado para interpretar a formação social brasileira a partir da identificação 
do ethos, calcado no princípio da miscigenação positiva por mistura. O “equilíbrio de antagonismos”, parte integrante e fundamental do ethos inglês, foi tomado por Freyre como modelo paradigmático para pensar o caso brasileiro.

O percurso de Freyre até Casa-Grande \& Senzala foi marcado por conflitos, hesitações e contradições. Segundo os indícios presentes em fragmentos de cartas e escritos autobiográficos, o jovem Freyre estava tomado pela angústia e mal-estar diante do desafio, internalizado como missão, de tornar-se um dos "homens fortes habilitados" a explicar/salvar o Brasil"; o racismo experimentado no exterior por ser mestiço; e o não pertencimento à estética ariana que tanto admirava. Esses conflitos invadiram o plano teórico de forma contraditória em dois aspectos: na mudança de ângulo ao interpretar o "problema" da mestiçagem brasileira do ponto de vista positivo, conferindo outro sentido às ideias absorvidas de seus interlocutores; e na abordagem que conserva o preconceito falando dele e produzindo um efeito de ruptura.

Como nos informa/ensina a Psicanálise, o sentimento racista opera em uma outra chave. Assim, o sentimento racista inconsciente de G.Freyre, formado e informado na infância no nordeste brasileiro, e sua anglofilia, provocaram conflitos de ordem subjetiva que sintomaticamente estão presentes na síntese que ele elaborou para interpretar o Brasil (Coelho, 2016; Rodrigues, 2008). Podemos identificar em várias momentos, da vida intelectual de nosso autor, o ideal de perfeição que condensa um dos pilares da ideologia tomista, segundo Gizlene Neder $(2000)^{8}$, no culto estético que Freyre fazia à cultura ariana da era vitoriana; na necessidade premente de corrigir e modificar, a posterior, seus escritos; na indefinição proposital quanto ao enquadramento em alguma área do conhecimento e na necessidade de escritos autobiográficos onde a idealização de seu EU deixa registrado o lugar a partir do qual ele queria ser visto e admirado.

$\mathrm{Na}$ interpretação positiva que fez da miscigenação no Brasil revelou, sem saber ou querer, o pathos (sofrimento, paixão, passividade) presente na formação social brasileira. ${ }^{9}$ No entanto, sua

\footnotetext{
${ }^{7}$ Missão salvífica do Brasil recebida e absorvida por influência decisiva do pai Alfredo Freyre (advogado, maçom eminente e educador ativista do ensino laico e técnico, que travou embates fervorosos com o Movimento de Reação Católica em Pernambuco, entre as décadas de 1920 e 1930), do irmão mais velho Ulysses Freyre (que também estudou na Baylor University, USA, e comungava das ideias do pai Alfredo) e do orientador intelectual Manoel de Oliveira Lima (eminente historiador, sociólogo e embaixador brasileiro, entusiasta das raízes ibéricas brasileiras, do iberismo e da hispanidade como projeto lusotropical. Assim, "o projeto civilizatório ibérico hispânico originalmente pensado por Oliveira Lima" foi "estendido ao seu pupilo, o jovem arguto Gilberto Freyre. Tal projeto alcançou seu apogeu em Casa-Grande \& Senzala, a obra germinal de Freyre, publicada em 1933. A eficácia ideológica do livro garantiu a Freyre reconhecimento no campo intelectual daquela conjuntura. Prova disso é que nos textos dedicados a pensar a americanidade, a partir de 1940, o autor ampliou sua interpretação do Brasil para a América Latina repetindo o sucesso já inaugurado em sua grande obra. Ademais, aplicando seu paradigma à realidade latino-americana e ampliando sua tese, Freyre cunhou a expressão Lusotropicalismo e realizou a busca por um ethos supranacional: um substrato de autenticidade como conteúdo cultural na formação de uma civilização moderna nos trópicos a partir da miscigenação. Eis uma contribuição decisiva do autor para pensarmos a americanidade e a latinidade da América Latina" (Cf. RODRIGUES e COELHO, 2021:201).

${ }^{8}$ Entendido aqui como conjunto de ideologias absolutistas que remetem a Santo Tomás de Aquino.

${ }^{9}$ Para uma conceituação mais precisa de pathos confira BERLINCK, 1997:17.
} 
narrativa mito-poética-epopeica ao revelar o pathos, a partir do ethos, produz como efeito políticoideológico o esvanecimento do pathos no processo de colonização europeia nas Américas. A constatação do ethos parece partir de uma predeterminação que concebe a história por meio de uma dimensão mitológica. ${ }^{10}$ A construção de uma identidade nacional a partir da miscigenação, vista como mistura, dificulta o discernimento entre as fronteiras étnicas. Na interpretação freyriana, a diversidade significa unicamente diferenciação, o que elimina a priori o antagonismo e o conflito. As partes são distintas, mas não justapostas, pois se misturam harmonicamente. Neste sentido, podemos dizer que o pensamento de Freyre possui uma dimensão tomista, já que elimina qualquer possibilidade de superação, guarda em si uma fantasia de perfeição e de pureza. A ideia de pacto implícita em CasaGrande \& Senzala está baseada na inclusão do português, do índio e do negro por mistura, o que implica diluição dos protagonistas. A integração entre as partes dirime o conflito e as várias formas de violências inerentes ao processo. Esse é o efeito ideológico que fará de sua obra um sucesso no Brasil e no estrangeiro.

\section{CONSIDERAÇÕES FINAIS}

A narrativa freyriana enaltece a conciliação, pois consiste em apresentar os antagonismos de forma equilibrada. Produz o apaziguamento das violências sofridas, suportadas e ignoradas, porém constituintes da formação da sociedade brasileira. Violências que impuseram marcas históricas em negros reduzidos a condição degradante de escravos. Um apaziguamento bem ao gosto do equilíbrio de antagonismos, tão apreciado pelo mestre de Apipucos ${ }^{11}$. Outrossim, provoca o encobrimento do pathos violento, posto que, o sofrimento decorrente do autoritarismo dos senhores de engenho fica "encoberto" pela aura sagrada, contemplativa e religiosa do pai autoritário e ausente. Assim, nossa interpretação da narrativa de Gilberto Freyre, a partir da repercussão da obra de Walter Pater, oferecenos uma janela para "olhar" o Brasil e os brasileiros em perspectiva temporal e pela circularidade de ideias, bem como pelo conservadorismo político, que cedo madrugou na formação do Brasil.

\footnotetext{
${ }^{10}$ A ideia de "predeterminação" contida em Casa-Grande \& Senzala pode ser entendida no sentido religioso.

${ }^{11}$ Bairro de Recife, Pernambuco, onde Gilberto Freyre viveu de 1940 até a sua morte em 1987.
} 


\section{REFERÊNCIAS}

BERLINCK, Manoel T. "O que é psicopatologia fundamental”. Psicologia: Ciência e Profissão. Vol. 17, N. 2, Brasília. 1997. pp. 13-20. Acesso em 20 de maio de 2021. Disponível em: $<$ https://www.scielo.br/scielo.php?script=sci_arttext\&pid=S1414-

98931997000200003\&lng=pt\&nrm=iso>

CERQUEIRA FILHO, Gisálio. Autoritarismo afetivo: a Prússia como sentimento. São Paulo: Ed. Escuta. 2005.

CERQUEIRA FILHO, Gisálio e CERQUEIRA, Marcelo N. Apetite pelo sagrado. Comunicação apresentada no III Congresso Internacional de Psicopatologia Fundamental e IX Congresso Brasileiro de Psicopatologia Fundamental. UFF. Niterói, RJ: 2008.

COELHO, Claudio M. Gilberto Freyre: indiciarismo, emoção e política na casa-grande e na senzala. Dissertação (Mestrado em História Social das Relações Políticas). PPGHIS, UFES, Vitória: 2007.

COELHO, Claudio M. Religião \& Política: Em nome do Pai: Gilberto Freyre e Casa-Grande e Senzala, um projeto político salvífico para o Brasil (1906-1933)? Tese (Doutorado em História Social das Relações Políticas). PPGHIS, UFES, Vitória: 2016.

FREYRE, Gilberto. Vida social no Brasil nos meados do século XIX. Tradução do original inglês, revista pelo autor, por Waldemar Valente. Recife: Instituto Joaquim Nabuco de Pesquisas Sociais; MEC. 1964.

FREYRE, Gilberto. Como e porque sou e não sou sociólogo. Brasília: Ed. da UNB. 1968.

FREYRE, Gilberto. Tempo morto e outros tempos: trechos de um diário de adolescência e primeira mocidade, 1915-1930. Rio de Janeiro: José Olympio. 1975.

FREYRE, Gilberto. Tempo de aprendiz: artigos publicados em jornais na adolescência e na primeira mocidade do autor, 1918-1926. São Paulo: IBRASA; Brasília: INL. 1979.

FREYRE, Gilberto. Casa-grande e senzala: formação da família brasileira sob o regime da economia patriarcal. 30 ed. Rio de Janeiro: Record. 1995.

GINZBURG, Carlo. "Sinais: raízes de um paradigma indiciário". In: Mitos, emblemas, sinais: morfologia e história. São Paulo: Cia das Letras. 1989. pp.143-179.

LARRETA, Enrique R. e GIUCCI, Guillermo. Gilberto Freyre: uma biografia cultural: a formação de um intelectual brasileiro: 1900-1936. Rio de Janeiro: Civilização Brasileira. 2007.

MARTINS, Mario R. Gilberto Freyre. O ex-protestante: uma contribuição biográfica. 2. edição. Goiânia: Kelps. 2011.

MENESES, Diogo de M. Gilberto Freyre: notas biográficas com ilustrações, inclusive desenhos e caricaturas. N.2. Série A. Coleção Estudos Brasileiros. Rio de Janeiro: CEB. 1944.

NEDER, Gizlene e SILVA, Ana Paula B. R. da. "Intelectuais, circulação de idéias e apropriação cultural: anotações para uma discussão metodológica". Passagens. Revista Internacional de História Política e Cultura Jurídica. Rio Janeiro. V.1, N.1, jan-jun. 2009. 
PALLARES-BURKE, Maria L. G. Gilberto Freyre: um vitoriano dos trópicos. São Paulo: Ed. UNESP. 2005.

PATER, Walter H. The child in the house. Portland, USA: Editor Thomas B. Mosher. 1909. Disponível em: <http://scans.library.utoronto.ca/pdf/1/19/childinhouse00pateuoft/childinhouse00 pateuoft_bw.pdf>

RODRIGUES, Marcia B. F. Ethos e pathos: violência e poder em 'Casa-Grande \& Senzala'. Menção honrosa. Concurso Pierre Fédida de Ensaios Inéditos de Psicopatologia Fundamental da Associação Universitária de Pesquisa em Psicopatologia Fundamental. Niterói: UFF. 2008. Disponível em: <http://www.fundamentalpsychopathology.org/pagina-ano-2008-259>

RODRIGUES, Marcia B. F. "Dilemas e agruras na passagem à modernidade: rede de sociabilidade, cultura religiosa e política (Barão do Rio Branco, Oliveira Lima e Gilberto Freyre)". Passagens. Revista Internacional de História Política e Cultura Jurídica. V.10, N.3, Niterói, setembrodezembro, 2018, pp.335-367. Acesso em: 21 de maio de 2021. Disponível em: <https://periodicos.uff.br/revistapassagens/article/view/46038>

RODRIGUES, Marcia B. F.; COELHO, Claudio M. "Gilberto Freyre e Manuel de Oliveira Lima: iberismo e hispanidade como projeto político lusotropical". Cap. 14. In: ALMEIDA, Flávio A. de (Org.). Ensino de História: Histórias, Memórias, Perspectivas e Interfaces. $1^{a}$ ed. Guarujá, SP: Científica Digital, 2021. pp.199-218.

SIEPIERSKI, Paulo D. "O ideário protestante nos artigos de jornal do aprendiz Gilberto Freyre". Comunicação \& Sociedade. São Bernardo do Campo: PósCom-Umesp, A.24, N.38, 2008. 2. sem. pp.85-106. 